\title{
WOMEN EMPOWERMENT DALAM PENGGUNAAN KB
}

\section{WOMEN EMPOWERMENT IN USING FAMILY PLANNING}

\author{
Dewi Andariya Ningsih \\ Akademi Kebidanan Ibrahimy Sukorejo Situbondo \\ Email :dewi14021@mail.unpad.ac.id
}

\begin{abstract}
ABSTRAK
Penentuan pilihan untuk mengunakan KB mencakup keterlibatan pasangan dalam mengambil sebuah keputusan yang mayoritas masih di kontrol oleh keputusan suami. Menurut ICPD 1994, keberlangsungan rancangan $\mathrm{KB}$ di Indonesia yakni perempuan memiliki posisi yang sebanding dan sejajar dalam penentuan opsi untuk mendayagunakan KB. Selain itu, pilihan dalam memanfaatkan media kontrasepsi sangat penting dipertimbangkan dari berbagai faktor yaitu faktor pasangan, kesehatan serta faktor alat kontrasepsi. Studi ini yakni merupakan tinjauan literatur untuk menganalisis tentang Women Empowerment dalam Penggunaan KB. Sumber untuk melakukan tinjauan literatur ini meliputi buku literatur, tesis dan studi pencarian sistematis database terkomputerisasi. Berdasarkan beberapa jurnal terdapat 2 bagian dari kajian artikel ini yaitu Women Empowerment dan penentuan pilihan dalam menggunakan KB. Women Empowerment yaitu memberdayakan perempuan dalam menentukan pilihan dalam pendayagunaan metode kontrasepsi. Sedangkan penentuan pilihan dalam menggunakan KB yaitu pertimbangan yang di pilih salah satunya (hanya suami atau hanya istri) atau keputusan tersebut didiskusikan bersama. Suami dan istri seharusnya mencari penjelasan yang akurat tentang kontrasepsi terlebih lagi terkait kesehatan reproduksinya sehingga bersama-sama berpartisipasi serta memperoleh utilitas yang sepadan dari petunjuk dan fasilitas KB Selain itu, pilihan menggunaan alat kontrasepsi sangatlah penting dipertimbangkan dari berbagai faktor yaitu faktor pasangan, kesehatan dan bagian alat kontrasepsi. Diharapkan kepada semua pasangan agar meningkatkan perhatian dan komitmen bersama dan tidak memandang gender dalam penentuan metode untuk menggunakan KB serta mendiskusikan permasalahkan kontrasepsi serta kesehatan reproduksi tanpa ada komponen yang menjadi preferensi dalam diskusi maupun penentuan kesimpulan dalam ber- KB.
\end{abstract}

\section{Kata Kunci : Women Empowerment, keputusan KB}

The determination of choice to use KB involves the involvement of a spouse in taking a decision that the majority is still in control by the husband's decision. According to ICPD 1994, the sustainability of $\mathrm{KB}$ planning in Indonesia is that women have equal and equal position in determining the option to utilize family planning. In addition, the choice in utilizing contraceptive media is very important to be considered from various factors, namely the couple's factors, health and contraceptive factors. This study is a literature review that tries to analyze the Women Empowerment in use family planning. Sources for conducting this literature review include literature books, theses and systematic search studies of computerized databases. Based on several journals there were two parts of the study of this article that was Women Empowerment and the determination of choice in using KB. Women Empowerment was empowering women in making choices in the use of contraceptive methods. While the determination of choice in using $\mathrm{KB}$ is the consideration in the choice of one (only husband or only wife) or the decision was discussed together. Husbands and wives should seek an accurate explanation of contraception especially related to reproductive health so that together participate and obtain equitable utilities from the instructions and family planning facilities In addition, the choice of use of contraceptives is very important to be considered from a variety of factors namely partner factors, health and parts contraception. It is desirable for all couples to promote mutual attention and commitment and regard not gender in determining methods for using family planning and discussing contraceptive and reproductive health issues without any component of preference in discussions or conclusions in KB.

Keywords: Women Empowerment, KB decision 
PENDAHULUAN

Masih tingginya jumlah penduduk di Indonesia sehingga berdampak pada kepadatan penduduk, sehingga pemerintah membentuk suatu stategi untuk mengurangi angka kelahiran yaitu dengan mengadakan program KB yang tujuannya untuk menurunkan angka kelahiran. Target utama dilaksanakannya rencana keluarga berencana yaitu keluarga. Kepala keluarga selaku pengambil keputusan yaitu suami, termasuk pengambilan keputusan bagi dirinya sendiri untuk menggunakan $\mathrm{KB}$ atau tidak, demi kesehatan reproduksinya secara otonom serta pasangannya.(Isti, 2010).

Salah satu hal yang mendukung terhadap pelaksanaan program pemerintah dalam memecahkan masalah kependudukan di Indonesia adalah dengan penetuan pilihan untuk pemakaian alat kontrasepsi dikeluarga. Keberhasilan strategi keluarga berencana didukung dari karakter pribadi baik istri maupun suami. Partisipasi utama dalam agenda KB salah satunya yaitu pemakaian alat kontrasepsi. Hal yang menjadi ketertarikan lebih yaitu dari dukungan terhadap pengintensifan potensi masyarakat dalam tata olah keluarga berencana (KB). Melalui perencanaan keluarga yang tepat persoalan kemasyarakatan yang akan timbul dapat ditangani dengan baik. Pemilihan penerapan kaidah kontrasepsi dalam keluarga tentu saja membutuhkan berbagai pertimbangan-pertimbangan, karena idealnya individu dapat memilih cara/alat mana yang cocok digunakan. Karakteristik pribadi dalam keluarga maupun karakteristik keluarga dapat memengaruhi pemilihan keputusan dalam pemanfaatan metode kontrasepsi.(Setiadi \& Iswanto, 2015).

Dalam penerapan program keluarga berencana itu sendiri perempuan cenderung dianggap sebagai objek. Hal ini berkorelasi dengan pencapaian sasaran program KB. Secara nyata, pihak yang paling merasa dirugikan oleh adanya pelaksanaan program KB yaitu perempuan. Hal ini berlandaskan fakta bahwa mayoritas macam - macam kontrasepsi di konstruksi untuk perempuan sehingga perempuan dijadikan landasan program KB (Marpaung, 2015). Semua pasangan tanpa memperhitungkan agama, umur, suku, sosial dan sebagainya memiliki kebebasan yang selaras untuk menetapkan secara bebas dan beresponsibilitas jika diilihat dari aspek hak reproduksinya. Sama hal nya dengan 
perempuan memiliki keleluasaan memastikan keputusan untuk ber-KB dan menentukan alat kontrasepsi yang akseptabel untuk dirinya.(Makarao, 2009).

Program KB Nasional tidak hanya berkiblat kepada persoalan penanggulangan pertumbuhan penduduk tapi untuk menaikkan nilai kehidupan dan kesejahteraan penduduk Indonesia. Tetapi sayangnya program $\mathrm{KB}$ belum seutuhnya dapat berfaedah dengan baik. Masih banyak kejadian yang tampak di lapangan misalnya, adanya ketidakcocokan tekhnik kontrasepsi yang digunakan, terlebih menimbulkan kekhawatiran terhadap bahaya kesehatan di akibatkan oleh pemilihan ketetapan pemakaian metode kontrasepsi yang bukan atas harapan sendiri serta informasi yang terbatas. Keputusan yang berbeda dapat ditimbulkan dari kognisi yang berbeda dari masing - masing pasangan terkait keluarga berencana. Tampaknya pemaksaan kehendak terhadap penentuan keputusan terjadi antar individu. Hal ini bisa terjadi karena kurangnya pengetahuan tentang karakteristik dari masing-masing individu tersebut. Sehingga keberlangsungan program keluarga berencana ditentukan oleh pengambilan keputusan yang munasabah (Setiadi \& Iswanto, 2015). Untuk itu hal pokok yang mesti dilakukan untuk meningkatkan pemenuhan mengenai tanggung jawab reproduksi untuk mengubah pola pikir yang salah dari kaum laki-laki tentang kebebasan reproduksi perempuan.

Hasil pemantauan yang dilakukan oleh penyusun pada bulan Januari - Maret 2017 pada sepuluh pasangan akseptor $\mathrm{KB}$ aktif di wilayah kerja Kecamatan xxx Kabupaten ABCD menunjukkan bahwa kebanyakan yang memakai alat kontrasepsi ialah perempuan. Hanya $10 \%$ pengguna KB laki-laki yaitu menggunakan kondom. Ada beberapa istri yang menuturkan bahwa suami mereka tidak tau menahu terkait alat kontrasepsi apa yang dipakai. Yang mereka tau hanya bagaimana tidak terjadi kehamilan. Sehingga pihak perempuan yang mencari solusi kontrasepsi apa yang akurat untuk dirinya. Alasan lainnya pihak laki-laki enggan ber KB karena budaya yang ada di sekelilingnya hanya perempuan yang menggunakan KB. Dan ada rasa kurang percaya diri apabila membahas kontrasepsi KB pada laki-laki. Kondisi ini sering kali menjadi penyebab pengambilan keputusan secara sepihak. 
Selain itu, kurang terjalinnya hubungan yang berkualitas antara pasangan suami dan istri.

\section{HASIL DAN PEMBAHASAN}

Di dalam suatu pernikahan, setiap pasangan selalu berperan serta dalam permasalahan yang melibatkan rumah tangga mereka seperti pengambilan keputusan. Pengambilan keputusan itu bisa berupa pendidikan, aturan yang berlaku di rumah tangga pendayagunaan penghasilan, penyaluran aspirasi termasuk keputusan dalam berkeluarga berencana (Osamor \& Grady, 2016). Dalam menetukan pilihan untuk memutuskan sesuatu seyogyanya dirundingkan oleh pasangan secara selaras untuk perkara krusial dan proporsi besar untuk kapasitas sebuah keluarga. Pengambilan keputusan secara umum tetap di kontrol oleh laki-laki karena mereka merasa memiliki peran sebagai pemimpin rumah tangga dan berkewajiban memberi penghidupan pada keluarga sehingga sesuatu hal yang berhubungan dengan penggunaan penghasilan tetap ditetapkankan oleh laki-laki misalnya kepemilikan rumah.(Hia, 2010).

Hal itu didukung oleh (Undangundang Republik Indonesia Nomor 1
Tahun 1974 Tentang Perkawinan, 1974) menetapkan bahwa peran suami adalah sebagai pemimpin dalam rumah tangga dan istri sebagai ibu rumah tangga. Suami wajib mengayomi istrinya, dan memberi segala sesuatu kebutuhan hidup berumah tangga sesuai dengan kapabilitasnya (pasal 34(1)).Sedangkan tugas istri adalah mengerjakan pekerjaan rumah tangga sebaik - baiknya (pasal 34(2)). Berdasarkan pengklasifikasian kapasitas tersebut, tugas perempuan yang sahih adalah peran kerumahtanggaannya sehingga memicu rendahnya pengambilan keputusan yang bersifat internal dan reproduktif, sedangkan suami berfungsi pada pengambilan keputusan dalam rumah tangga yang bersifat publik. Meskipun demikian, istri tidak sepenuhnya memiliki campur tangan pada pengambilan keputusan terkait hal-hal reproduksi sebagaimana kasus, sering terjadinya istri melakukan pengguguran kandungan karena permintaan suami. Hal tersebut memperlihatkan bahwa hakhak reproduksi perempuan masih dibawah kendali suami (Notoatmodjo, 2012) Hal ini sesuai dengan yang diungkapkan Saptiawan (2009) suami memiliki tanggung jawab yang sangat subtansial, terutama pada pengambilan 
keputusan berhubungan dengan reproduksi pasangannya termasuk dalam keputusan menggunakan $\mathrm{KB}$ dan menurut (Sulastri, 2013). Responsibilitas penentuan serta pemanfaatan alat kontrasepsi diserahkan semata-mata pada perempuan.

Peran perempuan masih diskriminatif untuk mengambil keputusan di dalam keluarga atau urusan regional keluarga, sedangkan suami masih sebagai orang yang menentukan kebijakan yang menonjol serta memiliki pandangan bahwa suami yang harus dihargai dalam pengambilan keputusan karena sudah konvensional dalam masyarakat serta diikuti secara turun menurun sebagai kepala keluarga (León, Lundgren, Sinai, Sinha, \& Jennings, 2014). Sedangkan pendidikan formal maupun tidak formal sangat berdampak pada penentuan pilihan dalam keluarga dimana perempuan yang bekerja mendongkrak pendapatan dan pengeluaran keluarga yang diharapkan tidak memprioritaskan pendidikan hanya untuk anak laki-laki saja tetapi memberi kesempatan kepada semua anak laki-laki dan perempuan (Larsson \& Stanfors, 2014). Pendidikan dapat meningkatkan penggunakan, dan mempromosikan alat kontrasepsi dan praktek-praktek kesehatan reproduksi (Samarakoon \& Parinduri, 2015).

Pengetahuan dan pemakaian alat kontrasepsi berkembang dengan meningkatkan pendidikan perempuan. Selanjutnya pemberdayaan tersebut cenderung untuk mempromosikan kesejararan antara laki-laki dan perempuan dengan meningkatkan pemberdayaan perempuan di domain publik (Nanda, Schuler, \& Lenzi, 2013). Hal ini menginstruksikan bahwa kapitalisasi dalam pendidikan perempuan merupakan strategi penting untuk meningkatkan kapasitas perempuan untuk menjadi diri mereka sendiri, yang merupakan harapan yang diinginkan dalam dan dari dirinya sendiri, serta berperan dalam meningkatkan standar hidup generasi sekarang serta masa depan di negara berkembang (Andalon, Williams, \& Grossman, 2014).

Kaum laki-laki masih menempatkan perempuan sebagai subordinat. Akibatnya mereka bahkan tidak bisa menetapkan pilihan penting terkait fungsi reproduksinya, seperti kapan mereka menikah, mengggunakan alat reproduksi yang cocok, serta memiliki anak dengan kuantitas dan jarak yang tepat dengan keadaan 
kesehatan reproduksi mereka. Desain sosial serta budaya yang ada di masyarakat juga menempatkan perempuan sebagai satu-satunya pemegang beban reproduksi karena hal itu dianggap sebagai kodrat kaum perempuan (Juliastuti, 2009). Saat ini pembangunan perempuan sedang ditingkatkan. Kita dapat melihat kedudukan perempuan Indonesia dan berbagai kedudukannya serta situasi taksis. Keberagaman kapasitas tersebut memperlihatkan bahwa perempuan Indonesia merupakan potensi yang terpendam apabila ditingkatkan kualitasnya dan diberikan peluang yang sama untuk berperan. Meskipun berbagai peradaban perempuan telah dapat terkonfigurasikan, pelaporan jumlah penduduk yang perempuan saat ini berdaya guna menduduki kapasitas yang strategis tetapi dalam sikap untuk menentukan pilihan masih sangat terbatas termasuk yang berhubungan dengan kesehatan dengan dirinya sendiri (Marpaung, 2015).

Dalam kehidupan sehari-hari keluarga berkali-kali bersinggungan dengan masalah pengambilan keputusan mengenai hal-hal yang berhubungan dengan kebutuhan anggota keluarganya. Pada umumnya, apabila hal tersebut menyangkut keperluan seluruh anggota keluarga, keputusan sebaiknya diambil dari hasil kesepakatan bersama, baik tentang isi keputusan maupun tentang siapa yang dianggap paling akseptebel untuk menentukan pilihan terakhir (Ihromi, 2009). Secara umum jika didasarkan pada tendensi masyarakat, citra seorang perempuan selalu diibaratkan lebih rendah daripada pria. Banyak fenomena yang mengungkapkan bahwa kebanyakan perempuan terkecualikan dari kewajibannya, posisinya di bawah dari laki-laki. Seharusnya perempuan dan pria mempunyai oportunitas dan keleluasaan yang sepadan dalam hak bersuara dan berpendapat dan mengaktualisasikan dirinya sehingga terwujud sebuah koherensi yang berfaedah (Mudzhar, 2009).

Persoalan penentuan pilihan sering terjadi pada keluarga yang terdiri dari suami dan istri yang sama-sama memiliki andil yang penting dalam rumah tangga. Potret keluarga yang berkuasa suami ditanamkan pada keluarga dengan nilai-nilai dan tindakan konservatif terhadap kedudukan perkawinan. Pemasukan suami yang lebih tinggi menjadikan suami mempunyai kapasitas finansial dalam 
keluarga, sebaliknya jika pendapatan suami sedikit, maka istri ikut berpartisipasi dalam pembuatan keputusan keluarga (Sutisna, 2010). Konstruksi sosial di masyarakat yang membagi-bagi tugas antara pria dan perempuan seringkali merugikan perempuan. Perempuan yang bekerja mengurusi rumah tangga tidak mendapatkan penghargaan secara ekonomi. Nilai perempuan sebagai ibu adalah suatu nilai yang sakral yang penuh dengan pengabdian. Terminologi tugas rangkap tiga yang dimiliki perempuan yaitu : peran profitabel (mencari nafkah), peran reproduktif (mempersiapkan semua kebutuhan keluarga baik suami maupun anak anak), serta kapasitas kemasyarakatan (arisan dan pengajian) (Daulay, 2010).

Ditinjau dari sisi hak reproduksi tersurat bahwa setiap individu baik lakilaki maupun perempuan tanpa melihat kelas, sosial, suku, umur, agama, dan lain-lain memiliki hak yang sama untuk menentukan secara independen dan berkomitmen. Dengan kata lain dapat diterangkan bahwa setiap perempuan mempunyai kewenangan memutusan untuk menggunakan KB dan menetapkan metode kontrasepsi yang cocok untuk dirinya (Everet, 2012). Hak untuk menggunakan kontrasepsi adalah komponen dari hak kesehatan reproduksi dan tidak dapat di abaikan. Walaupun penentuan mufakat dalam pendayagunaan kontrasepsi dilakukan bersama sama antara pasangan tetapi masih di pengaruhi oleh suami sehingga menunjukkan kurangnya woment Empeworment (Kibira, Ndugga, Nansubuga, Sewannonda, \& Kwagala, 2014).

Menurut hasil penelitian bahwa dukungan suami mempunyai hubungan dalam menetukan pilihan penggunaan metode kontrasepsi, tetapi suami belum berkontribusi dalam pemilahan cara atau jenis alat kontrasepsi. Hal ini dipengaruhi beberapa faktor misalnya kurang pengetahuan suami terkait metode kontrasepsi dan pentingnya pemberian dukungan dalam memilih alat kontrasepsi, kegiatan suami dalam mengaktualkan perannya sebagai pemimpin dalam keluarga dalam mencari nafkah untuk memenuhi keperluan keluarga. Hal ini sesuai dengan konsep (Friedman, Bowden, \& Jones, 2010). Faktor yang mempengaruhi adanya dukungan suami yaitu tahap perkembangan, tingkat pengetahuan, faktor emosi, faktor spiritual, implementasi di keluarga, 
tingkat sosial ekonomi dan faktor latar belakang budaya. Penelitian (Isti, 2010) menunjukkan faktor yang mempengaruhi dukungan suami salah satunya yaitu tingkat pengetahuan, dimana semakin baik tingkat pengetahuan suami tentang alat kontrasepsi maka semakin efektif pula dukungan yang diberikan suami dalam menetukan alat kontrasepsi. (Nuryati \& Fitria, 2014) juga mengungkapkan ada kaitan yang berpengaruh antara dukungan suami dengan pemilahan alat kontrasepsi. Sehingga, dapat disimpulkan bahwa semakin tinggi pengayoman dari suami. maka semakin tinggi pula prosentase penerapan metode kontrasepsi yang tepat dengan individualitas dan kebutuhan.

\section{SIMPULAN DAN SARAN}

Penentuan pilihan dalam penggunaan $\mathrm{KB}$ sangat dipengaruhi oleh Women Empowerment yang ditunjukkan dengan dominasi suami dalam pemilihan kontrasepsi dan penentuan keputusan yang kurang berpihak kepada perempuan. Sehingga perlunya kontribusi suami dalam menentukan KB apa yang tepat digunakan.

Saran penelitian ini yaitu seluruh pasangan agar menerima pendapat, merespon, menghargai dan mempunyai kewajiban bersama terhadap hak-hak reproduksi dalam penggunaan $\mathrm{KB}$ khususnya menentukan pilihan untuk menggunakan $\mathrm{KB}$ agar tercapai fungsi reproduksi secara sehat dan aman dan tidak memandang gender dalam menentukan pilihan untuk mengggunakan KB.

Bagi tenaga kesehatan diharapkan agar tetap memberikan pengarahan dan diseminasi pada setiap pasangan yang ingin menggunakan $\mathrm{KB}$ khususnya dalam pengambilan keputusan. Masyarakat hendaknya senantiasa berusaha meningkatkan pengetahuannya tentang kontrasepsi, mengikuti konseling dan pertemuanpertemuan yang dibuat oleh Puskesmas maupun tenaga kesehatan, sehingga masyarakat mengetahui jenis, manfaat, kelebihan, kelemahan dan efek samping kontrasepsi dan masyarakat dapat memilih jenis kontrasepsi yang cocok sesuai dengan kespesifikan dan keperluan masyarakat.

\section{DAFTAR PUSTAKA}

Andalon, M., Williams, J., \& Grossman, M. 2014. Working Paper : Empowering Women: The Effect of Schooling on Young Women's Knowledge and Use of Contraception. IZA.

Daulay. 2010. Perempuan dan Kemelut Gender. Medan: USU Press.

Everet, S. 2012. Buku Saku Kontrasepsi 
dan Kesehatan Seksual Reproduktif. Jakarta: Penerbit Buku Kedokteran EGC.

Friedman, M. ., Bowden, V. ., \& Jones, E. G. 2010. Buku Ajar Keperawatan Keluarga: Riset, Teori dan Praktek. Jakarta: EGC.

Hia. 2010. Hak Kesehatan Reproduksi Perempuan di Kecamatan Mandrehe Kabupaten Nias Barat Tahun 2010. Tesis Program Studi Magister Ilmu Kesehatan Masyarakat Program Pasca Sarjana Universitas Sumatera Utara.

Ihromi, T. O. 2009. Para Ibu Yang Berperan Tunggal Dan Yang Berperan Ganda. Jakarta: FEUI.

Isti, H. 2010. Studi Deskriptif Faktor Faktor yang Mempengaruhi Dukungan Suami dalam Pemilihan Metode Kontrasepsi Jangka Panjang (MKJP) di Kelurahan Sekarang Kecamatan Gunung Pati Kota Semarang. Universitas Diponogoro.

Juliastuti, D. 2009. Pengambilan Keputusan Pemakaian Kontrasepsi Pada Ibu Grande Multipara Di Kabupaten Tangerang: Studi Grounded Theory.

Kibira, S. P. S., Ndugga, P., Nansubuga, E., Sewannonda, A., \& Kwagala, B. 2014. Contraceptive Uptake Among Married Women in Uganda: Does Empowerment Matter? African Popuation Studies, 28(2), 968-977.

Larsson, C., \& Stanfors, M. 2014. Women , $\mathrm{s}$ Education, Empowerment, and Contraceptive Use in $s$ ub- Saharan Africa: Findings from Recent Demographic and Health Surveys. African Population Studies, 28(2), 10221034.

León, F. R., Lundgren, R., Sinai, I., Sinha, R., \& Jennings, V. 2014. Increasing Literate and Illiterate Women , s Met Need for
Contraception Via Empowerment: A Quasi-Experiment in Rural India. Reproductive Health, 11(74), 1-10. Retrieved from http://www.reproductive-healthjournal.com/content/11/1/74RESEA $\mathrm{RCH}$

Makarao, N. R. 2009. Gender dalam Bidang Kesehatan. Bandung: Penerbit Alfabeta.

Marpaung, L. F. B. 2015. Faktor-Faktor Yang Berhubungan Dengan Pengambilan keputusan Untuk BerKB Pada Pasangan Usia Subur (PUS) Di Kelurahan Harjo Sari 1 Kecamatan Medan Amplas Tahun 2014.

Mudzhar. 2009. Kepemimpinan Wanita dalam Perspektif Agama dan Sejarah Islam. Yogyakarta: Pustaka Pelajar.

Nanda, G., Schuler, S. R., \& Lenzi, R. 2013. The Influence Of Gender Attitudes On Contraceptive Use In Tanzania: New Evidence Using Husband's And Wives' Survey Data. J. Biosoc, 45(May), 331-344. http://doi.org/10.1017/S002193201 2000855

Notoatmodjo, S. 2012. Promosi Kesehatan dan Perilaku Kesehatan. Jakarta: Penerbit Rineka Cipta.

Nuryati, S., \& Fitria, D. 2014. Hubungan antara Pengetahuan Suami tentang $K B$ dengan Partisipasi Suami dalam ber-KB di Kelurahan Kemang Kabupaten Bogor. Stikesnh.ac.id.

Osamor, P. E., \& Grady, C. 2016. Women' $s$ Autonomy in Health Care Decision- Making in Developing Countries : A Synthesis of the Literature. International Journal of Women's Health, 8, 191-202.

Samarakoon, S., \& Parinduri, R. A. (2015). Does Education Empower Women? Evidence from Indonesia. 
Elsevier, $\quad 66, \quad 428-442$. http://doi.org/10.1016/j.worlddev.2 014.09.002

Saptiawan. 2009. Gender dan Inferioritas Perempuan. Yogyakarta: Pustaka Pelajar.

Setiadi, \& Iswanto, L. 2015. Pengambilan Keputusan Penggunaan Alat Kontrasepsi Istri Dalam Keluarga. Populasi, 23, 2034.

Sulastri, S. 2013. Hubungan Dukungan Suami dengan Minat Ibu dalam Pemakaian Kontrasepsi IUD Di Bergas. E-Jurnal Gizi Dan Kesehatan Ngudi Waluyo Ungaran, 2, 64-72.

Sutisna. 2010. Perilaku Konsumen dan Komunikasi Pemasaran. Bandung: PT Remaja Rosdakarya.

Undang-undang Republik Indonesia Nomor 1 Tahun 1974 Tentang Perkawinan. 1974. 